\title{
Psoriasis and Guillain-Barré Syndrome: Incidental or Associated?
}

\author{
Betül SARGIN, Gülcan GÜRER
}

Department of Physical Medicine and Rehabilitation, Medical Faculty of Adnan Menderes University, Aydın, Turkey

Guillain-Barré syndrome (GBS) is an acute autoimmune inflammatory demyelinating polyneuropathy. ${ }^{1}$ Psoriasis is an inflammatory disease characterized by lesions of the skin, nails, and joints. ${ }^{2}$ In this article, we report a male patient with psoriasis presenting with GBS.

A 66-year-old male patient presented to the emergency department with complaints of numbness, tingling, and weakness in his legs since last two hours. The patient had a history of chronic plaque psoriasis affecting the lower limbs (Figure 1). On neurological examination, his dorsiflexor strength of right ankle was $4 / 5$ and eversion strength of left ankle was 3/5. His vibratory sense was decreased on lumbar 3 and 4 dermatomes in left lower extremity. Deep tendon reflexes were normal on upper extremities; but patella reflexes were decreased in the lower extremities. The patient's laboratory studies did not reveal any infectious process. His cerebrospinal fluid studies revealed protein count of $35.8 \mathrm{mg} / \mathrm{dL}$ and glucose of $60 \mathrm{mg} / \mathrm{dL}$ with normal cell count. Cerebrospinal fluid cultures were sterile. Nerve conduction studies of the patient reported early stage acute inflammatory demyelinating polyneuropathy (Table 1). He fulfilled the Brighton criteria for GBS. ${ }^{3}$ After GBS diagnosis, therapy with intravenous human immunoglobulin was instituted in addition to methotrexate (15 mg/week), folic acid ( $5 \mathrm{mg} /$ week), and pregabalin $(600 \mathrm{mg} /$ day). He recovered gradually over the next three weeks gaining a muscle power of 5 in lower limbs. He showed significant improvement functionally and became able to walk independently. He was discharged from the hospital and the patient was called for a control visit two weeks later.

Neurologic disorders of psoriasis are rare manifestations. ${ }^{4-6}$ To our knowledge, this is the first psoriasis patient presenting with GBS. When neurologic dysfunctions develop in patients with psoriasis history, the possibility of GBS should be

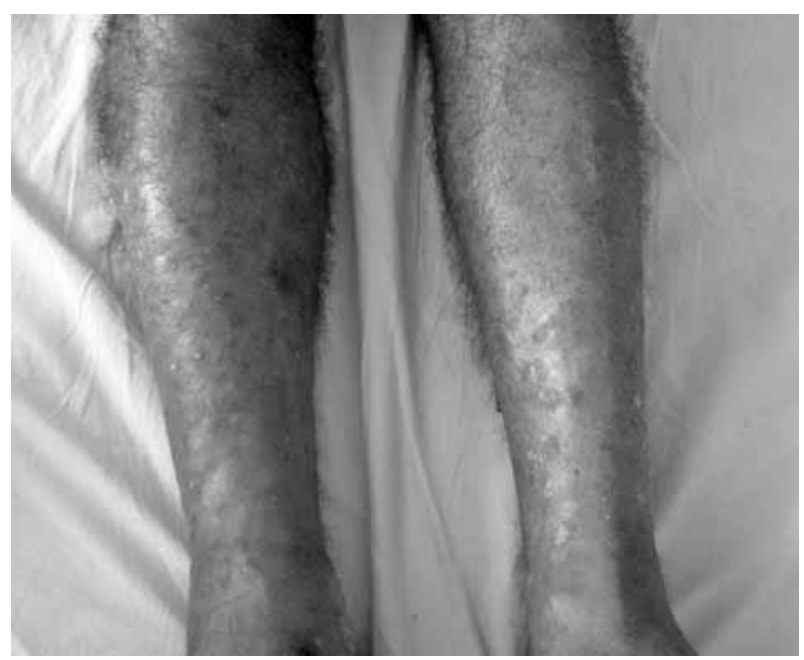

Figure 1. Chronic plaque psoriasis affecting the lower limbs. 


\begin{tabular}{|c|c|c|c|}
\hline Anatomic site & Amplitude (mV) & Latency (ms) & Conduction velocity $(\mathrm{m} / \mathrm{sec})$ \\
\hline \multicolumn{4}{|c|}{ Right median motor } \\
\hline Wrist & 11.2 & 2.6 & 52.3 \\
\hline Elbow & 8.9 & 7.0 & \\
\hline \multicolumn{4}{|c|}{ Right ulnar motor } \\
\hline Wrist & 19.8 & 1.50 & \\
\hline Elbow & 19.1 & 6.2 & \\
\hline Axilla & 18.6 & 7.3 & \\
\hline Erb's point & 14.9 & 10.4 & \\
\hline \multicolumn{4}{|c|}{ Right tibial motor } \\
\hline Ankle & 6.5 & 7.6 & 32.0 \\
\hline Knee & 4.3 & 17.9 & \\
\hline \multicolumn{4}{|c|}{ Left tibial motor } \\
\hline Ankle & 1.6 & 4.4 & 35.1 \\
\hline Knee & 0.4 & 15.8 & \\
\hline \multicolumn{4}{|c|}{ Left peroneal motor } \\
\hline Ankle & 4.5 & 4.2 & 36.1 \\
\hline Knee & 4.5 & 12.5 & 62.5 \\
\hline \multicolumn{4}{|c|}{ Left sural sensory } \\
\hline Ankle & 4.0 & 3.2 & 41.9 \\
\hline Calf & 3.7 & 3.1 & \\
\hline
\end{tabular}

kept in mind and the patients should be examined in this respect.

\section{Declaration of conflicting interests}

The authors declared no conflicts of interest with respect to the authorship and/or publication of this article.

\section{Funding}

The authors received no financial support for the research and/or authorship of this article.

\section{REFERENCES}

1. Li Z, Shen J, Liang J, Feng F. Successful surgical treatment of scoliosis secondary to Guillain-Barré syndrome: Case report. Medicine (Baltimore) 2016;95:3775.
2. Atyabi A, Shirbeigi L, Eghbalian F. Psoriasis and Topical Iranian Traditional Medicine. Iran J Med Sci 2016;41:54.

3. Fokke C, van den Berg B, Drenthen J, Walgaard C, van Doorn PA, Jacobs BC. Diagnosis of GuillainBarré syndrome and validation of Brighton criteria. Brain 2014;137:33-43.

4. Polienko EM, Pavlova TI, Getagazov ME. Neurologic disorders in patients with psoriatic arthropathy. Revmatologiia (Mosk) 1988;1:43-7. [Abstract]

5. Bartsch T, Rempe T, Wrede A, Leypoldt F, Brück W, Adams $\mathrm{O}$, et al. Progressive neurologic dysfunction in a psoriasis patient treated with dimethyl fumarate. Ann Neurol 2015;78:501-14.

6. Zhu TH, Nakamura M, Farahnik B, Abrouk M, Lee $\mathrm{K}$, Singh R, et al. The Role of the Nervous System in the Pathophysiology of Psoriasis: A Review of Cases of Psoriasis Remission or Improvement Following Denervation Injury. Am J Clin Dermatol 2016;17:257-63. 